\title{
NEW SOURCES OF EMPLOYMENT TO PROMOTE THE WEALTH-GENERATING CAPACITY OF RURAL COMMUNITIES
}

\author{
Miklós Pakurár, Judit Oláh \& András Nábrádi \\ University of Debrecen Centre for Agricultural and Applied Economic Sciences \\ Faculty of Applied Economics and Rural Development \\ Department of Organisation and Logistics
}

\begin{abstract}
New Sources of Employment to Promote the Wealth-Generating Capacity of Rural Communities (acronym: RuralJobs) is a collaborative research project partly funded under the European Commission Research and Development 7th Framework Program. The RuralJobs consortium consists of partners drawn from eight European Union (EU) countries (Bulgaria, France, Hungary, Italy, Lithuania, Romania, Spain and UK). The project began on February 2008 and finished in October 2010. RuralJobs quantified labour market, demographic and economic trends, and the impact of employment creation measures and policies in seven, representative "reference areas" across the EU, and used the information to demonstrate how rural development measures can be better targeted and how rural development policies should evolve. We identified labour market, demographic and economic trends in rural areas across EU-27 and the potential for new sources of employment outside traditional primary and secondary sector activities, and examined the interaction between different types of rural area (peri-urban, remote, high environmental/amenity value etc.). We identified employment growth areas where rural development programmes can be targeted to increase their contribution to employment creation. Our strategic objectives were the following: review of employment policies and programmes, scenarios for new sources of employment according to rural typologies, recommendations for better targeting of strategies, dissemination and mainstreaming. The main outcome expected is that the results will allow a better targeting of rural development measures and future evolution of rural development policies in line with the Lisbon Strategy.
\end{abstract}

Key words: RuralJobs, rural employment, labour market, strategies

\section{Introduction}

Fifty-six per cent of the population of the 27 Member States of the European Union (EU) live in rural areas representing $91 \%$ of its territory. This is why rural development is so vitally important. Article 158 of the consolidated version of the current Treaty, on economic and social cohesion, establishes that "the Community shall aim at reducing disparities between the levels of development of the various regions and the backwardness of the less favoured regions or islands, including rural areas".

RuralJobs quantified the employment needs and potentials in different typologies of pilot areas within contrasting reference areas in seven countries, evaluating the effectiveness of past and current policies in addressing these needs and potentials, and by systematic analysis of the results, providing guidelines on the better targeting of future rural development measures.

The RuralJobs consortium consisted of partners drawn from eight European Union (EU) countries. The partners were selected on the basis of the following criteria: a track record of previous cooperation, geographical distribution and complementary skills (Fieldsend, 2008). The partners of RuralJobs:

- University of Debrecen, Hungary, the Coordinator,

- University of Plymouth Higher Education Corporation, UK,

- Universitatea Babes Bolyai, Romania,

- Lithuanian University of Agriculture, Lithuania,

- Consejeria de Agricultura y Pesca - Junta de Andalucia, Spain,

- Conseil Regional de Limousin, France,

- Institute of Agricultural Economics, Bulgaria, and

- Istituto Nazionale Istruzione Professionale Agricola, Italy.

RuralJobs has four strategic objectives:

- review of employment policies and programmes,

- scenarios for new sources of employment according to rural typologies,

- recommendations for better targeting of strategies, and

- dissemination and mainstreaming. 


\section{Methodology}

\subsection{The division of tasks}

RuralJobs is divided into 'work packages' (WPs), of which WP1 is project management and WP7 covers all dissemination activities (Fieldsend, 2008).

There are five research-based WPs: WP2 'Assessment of labour market policies and programmes', WP3 'Assessment methodologies and indicators', WP4 'Typology for regions', WP5 'New strategies for employment in pilot areas' and WP6 'Synthesis of recommendations'.

\section{WP2. Assessment of labour market policies and programmes}

WP2 was designed to review the current state of knowledge relating to rural employment in the EU.

\section{WP3. Assessment methodologies and indicators}

The objective of WP3 was to select methodologies that can be used to collect, from the study areas, the necessary data to assess, on the basis of a recognised set of indicators, labour market, demographic and economic trends, the impact of employment creation measures and policies in the reference areas and top-down and bottom-up constraints on their effectiveness. The work package was divided into two tasks.

\section{WP4. Typology for regions}

In order to challenge the 'one size fits all' position, a framework is needed in which we can demonstrate that different types of region require a different policy approach to rural employment. Thus, WP4 interprets the field research results of RuralJobs WP5 in terms of a regional typology.

\section{WP5. New strategies for employment in pilot areas}

The objectives of this WP were to identify labour market, demographic and economic trends in a selection of representative pilot areas an to identify employment growth areas in the context of available human capital, skills and adaptability as well as demand for labour and existence of top-down and bottom-up constraints.

\section{WP6. Synthesis of recommendations}

This WP collects all results from all WPs, producing a set of recommendations with the aim of helping decision makers at the EU, national and regional levels to better target rural employment development strategies and programmes.

\section{WP7. Dissemination and technical assistance for mainstreaming}

WP7 manages all activities associated with dissemination, exploitation, marketing and long term maintenance of the results of the project and provides technical assistance and a framework for the mainstreaming of good practices identified and developed through the project.

The main products are the following:

- Collaborative platform. Agora-Project (http://www. agora-project.net/), a flexible and evolutionary web application composed of several modules, has been chosen as a tool for sharing information and collaborative work.

- Website. This is structured by the following main pages: background, objectives, methodology, workpackages, publications, partners, links, and contacts. The deliverables are being posted on the site in PDF format. The website went online in January 2009.

- Newsletter. The first newsletter was sent out in August 2009 to all contacts identified in a deliverable and via partners' own mailing lists.

\subsection{The RuralJobs typology and rationale behind it}

The main purpose of rural typologies is to ensure that policies for rural areas are based on a fundamental recognition that the issues that they are seeking to address are multi dimensions. It is important to explore the range of issues of concern, the way in which the typology will be used and the scale at which data are available to avoid the practical problems of typology development and its implementation.

The typology chosen for RuralJobs (Raupelien , 2009) was applied at NUTS3 level and was based on an EU DG Regio study (Dijkstra and Poelman, 2008) which combines a new classification of remoteness, based on accessibility measured by driving time to the closest city (of 50,000 inhabitants or more), with the OECD classification of rurality based on population density (OECD, 1994). RuralJobs combined this with the criterion of competitiveness of region, which is measured by GDP per capita. The result is twelve 'types' of NUTS3 region of which four are urban, two are very few intermediate, remote regions regardless of level of GDP, and six 'types' of rural area which occur widely.

The choice of 50\% as the GDP threshold, rather than $75 \%$ which is currently used by the EU at NUTS2 level to define 'convergence' and 'competitiveness and employment' regions, reasonably clearly divided the regions of the EU-15 and the New Member States (NMS) from Eastern Europe into separate groups. RuralJobs deliverable D2.1. (Pakurár and Kovács, 2008) has demonstrated major differences in the characteristics of the rural labour market of the two types of region.

The research undertaken in the RuralJobs project was founded on three hypotheses:

1. That a territorial approach to improving the wealth generating ability of rural areas through the creation of new sources of employment is required, whilst recognising the uniquely important role of agriculture and other land-based industries in the rural economy.

2. Initiatives to create new sources of employment in 
rural areas must take full account of the existence of markets for the products of labour, whether these are in the primary, secondary or tertiary sectors. Frequently, the largest markets are in urban areas

3. Rural areas in different parts of the EU are fundamentally different from each other in many respects and that a single, EU-wide "solution" or "strategy" for creation of rural employment is not appropriate. Through the study of a representative selection of "reference areas" it may be possible to identify a set of general principles which can be applied in varying combinations to different typologies of rural area.

The RuralJobs typology therefore addresses all three RuralJobs hypotheses and is an adequate framework within which results must be interpreted. We recognised that the Dijkstra and Poelman (2008) study was work in progress, but we felt that the merits of using a 'recognised' EU methodology outweighed its possible weaknesses.

According to the typology, of the 'high GDP' EU NUTS3 regions, $15 \%$ of all EU regions are 'predominantly rural accessible', $8 \%$ are 'predominantly rural - remote' and $29 \%$ are 'intermediate - accessible'. Of the 'low GDP' regions, 6\% are 'predominantly rural - accessible' $3 \%$ are 'predominantly rural - remote' and 6\% are 'intermediate - accessible'. The remaining 32\% of EU NUTS3 regions are 'predominantly urban' (Raupelien , 2009).

Seven of the eight RuralJobs partners undertook field research in pilot areas. Thus all six most common rural 'types' of region were included in the research:

- 'high GDP - urban - accessible' and 'high GDP intermediate - accessible' (UK),

- 'high GDP - predominantly rural - accessible' and 'high GDP - predominantly rural - remote' (France),

- 'high GDP - intermediate - accessible' and 'high GDP - predominantly rural - remote' (Spain),

- 'low GDP - intermediate - accessible' (Bulgaria),

- 'low GDP - predominantly rural - accessible' and 'low GDP - predominantly rural - remote' (Hungary),

- 'low GDP - intermediate - accessible' and 'low GDP

- predominantly rural - accessible' (Lithuania), and 'low GDP - predominantly rural - remote' (Romania).

The RuralJobs review of previous relevant researches (Sabau and Paquiet, 2009) noted many different approaches to defining the boundaries of study areas for field research. Frequently, administrative boundaries (NUTS2, NUTS3 or NUTS4) were used. As our research was expected to "examine the interaction between different types of rural areas (peri-urban, remote, high environmental/ amenity value etc.) and the evolution of labour markets, travel to work areas and changing work patterns", we opted to use 'labour market' or 'employment' areas. Remarkably, in most countries represented in the RuralJobs research, evidence was available which allowed these areas to be defined, as follows: 'Travel to Work Areas' (TTWA) in the UK (Bond and Coombes, 2007); 'Local Labour Systems' (LLS) in Hungary (Radvánszki and Sütő, 2007); and 'agglomeration areas' in Bulgaria (Anon., 2007). In France, a 'Pays' is the result of a collective bottom-up approach with regional approval of its boundary. Only in Romania was it necessary to use an administrative territory (a NUTS 3 region) as a pilot area. Inevitably, the methodology used to define labour market areas is different in the different countries.

It was sometimes less easy to define which parts of the pilot area were rural. It is widely accepted (e.g. Kerekes, 2010) that a single definition of 'rural' does not exist. Thus, as with labour markets, different RuralJobs partners adopted different definitions of 'rural' but again this is not a serious problem. In all pilot areas, rural areas share two sets of properties giving a degree of homogeneity:

- They have relatively low population densities.

- Their landscapes are dominated by landforms linked to the natural environment.

\subsection{The DPSIR Model: Driving forces - Pressure - State - Impact - Response}

This increasing interest in rural employment beyond agriculture must be accompanied by a better understanding of the relevant factors and processes in rural economic development, and the relationships between them. One approach to this, which has been successfully applied in other contexts, is to use the driving force, pressure, state, impact and response (DPSIR) model as a framework. RuralJobs has adopted the DPSIR model as a tool to show the link between 'driving forces' which affect employment and economic prosperity, and policy responses. (Fieldsend, 2009)

In the model (Figure 1), rural employment (jobs per person) represents the state. Employment has an impact on economic prosperity and other issues such as social cohesion, and these in turn influence policy responses (and other, such as socio-economic). These responses may be

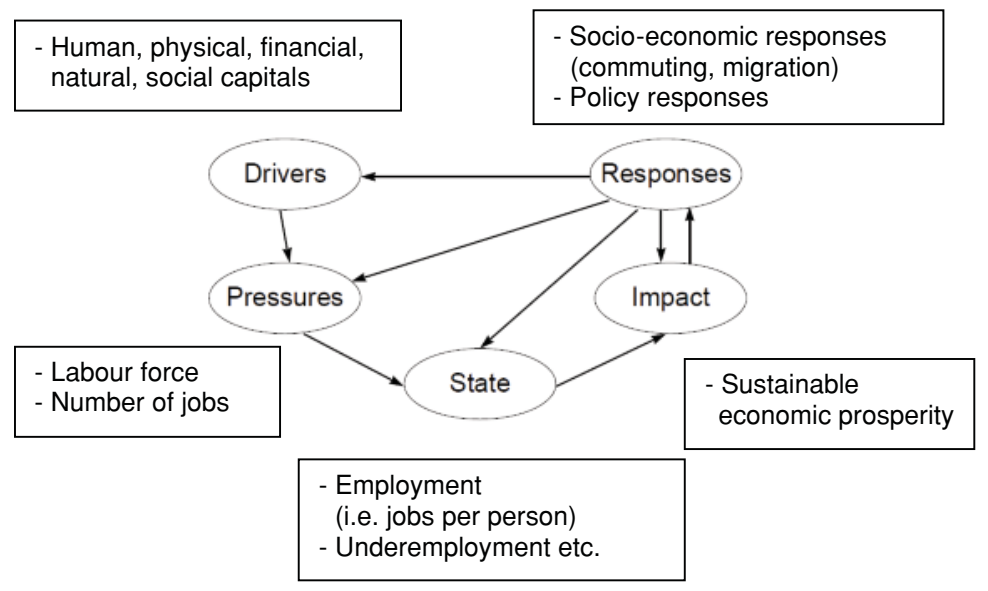

Figure 1. The DPSIR framework as applied to rural employment in the RuralJobs project 
targeted either at the driving forces which in turn influence the pressures on employment, i.e. supply of labour (working age population) and supply of jobs (economic activity); directly at the creation of more and better jobs, or even at the state, by connecting the offer with the demand (e.g. through jobcentres). In all ways, policy responses can lead to an increase in employment in rural areas which in turn would have a positive impact in terms of their sustainable economic prosperity. This approach is extremely policy-relevant as economic prosperity is a key objective of the EU Sustainable Development Strategy.

Driving forces can be categorised in several different ways, but are frequently characterised as five 'capitals', namely natural, human, social, physical and financial (e.g. Alkan Olsson et al., 2004). Although the term 'capital' is used, most of the assets are not capital stocks in the strict economic sense of the term. The term 'capital' is used because this is the common designation in the literature (DFID, 1999). Simple and employment-focused definitions of these 'capitals' are as follows:

- Human capital is defined as the skills and knowledge possessed by workers.

- Social capital is defined as the networks of relationships between people, firms, and institutions in a society, together with associated rules of conduct, trust, cooperation, etc., that enable a society to function effectively.

- Financial capital is defined as money used by entrepreneurs and businesses to buy what they need to make their products or provide their services.

- Natural capital is defined as a stock of natural resources used for production.

- In general, physical capital refers to any non-human asset made by humans and then used in production.

A set of 40 indicators was compiled, as a framework for the Task 5.1. research. Partners were asked to present data (at LAU2 level where possible) in Deliverable 5.1. for four indicators describing pressures, six describing state and four describing impacts in a form which demonstrates any differences between the performance of rural areas and urban centres (indicators 15-28 in Fieldsend, 2010). Fourteen indicators (numbers 1-14) of driving forces constituted an indicative list of topics which may arise during the interviews in the pilot areas and, if so, which should be discussed in D5.1. Employment issues which can be difficult to quantify (e.g. underemployment, employment in the informal economy) through lack of data (numbers 29-36) were also to be addressed in a qualitative way. Finally, the research also touched on major non-policy responses (such as commuting and migration) specified by indicators $37-40$.

\subsection{Field research methodology}

The field research was expected to interpret the rural employment situation in the pilot area in order to conclude whether any employment problem of a specific rural nature existed (and, if so, in what form), and to identify employment growth areas in the context of available human capital, skills and adaptability as well as demand for labour and existence of top-down and bottom-up constraints.

The method proposed for the pilot area field research was a case study, a complex method, which includes a variety of quantitative and qualitative methods. The following methods were used during the field research: secondary analysis of statistical data and relevant literature (reports, strategies, studies, monographs etc.) about the pilot area, semistructured interviews with key informants and structured interviews for recording information about successful initiatives for employment creation ('good practices') identified in the pilot area, as well as SWOT analysis and SOR analysis (involving also focus group meetings) to evaluate the employment development potential of the pilot areas. The methodological framework used is fully described by Vincze et al. (2009).

For collecting quantitative data no specific tools were developed; influenced by the availability of statistical data at LAU2, LAU1 and NUTS3 levels, partners built up their own databases.

Primary data was collected through interviews. To maximise consistency between the partners, in all pilot areas the same interview guide was used. Around 20 interviewees with expert knowledge of rural employment issues were selected in each pilot area (although not all interviewees were based in the pilot area), including decision makers (elected representatives of administrative units relevant for the pilot area), local government experts, other experts (e.g. academics, consultants), representatives of community organisations/NGOs and of the business sector (e.g. Chamber of Commerce, Farmers' Union, private companies).

The subject of the SWOT analysis was the rural labour market in the pilot area. Thus the 'internal audit' i.e. the Strengths and Weaknesses, was based on the assets of the pilot area, and the 'external audit' i.e. the Opportunities and Threats was based on drivers which do, or which are likely to, affect rural employment in the pilot area.

In each pilot area a draft list of components of the SWOT was prepared from the results of the quantitative data analysis, interviews and review of existing reports; this was circulated for validation to the interviewees, who were asked to select the five most important factors from each group. On the basis of the feedbacks received, the draft SOR matrix was compiled, which was again circulated to the interviewees. The importance to rural employment in the pilot area of the relationship between each Strength/Weakness and Opportunity/Threat was scored on a 0-3 scale where 0 means not important and 3 means extremely important. For each of the relationships obtaining high scores from most of the interviewees, an 'operational objective' (a concrete way to face / give an answer to the issue) was drafted.

The provisional SOR matrix results and the draft wording of the operational objectives were validated at focus group meetings (one or two per pilot area), attended by interviewees and other key local stakeholders. The validated operational objectives were then clustered into a series of 
'strategic orientations' which could be the focus for future strategy development in the pilot area.

\section{Results and discussion}

\subsection{Strategic orientations for rural job creation}

The strategic orientations formulated by the RuralJobs research can be grouped into five 'top level' strategic orientations for rural job. While the first two strategic orientations underpin the improvement of human capital and the development of infrastructure, the three subsequent ones focus on the mobilisation of the natural capital of rural areas through the development of key growth sectors, the reinforcement of local economy and the improvement of governance.

\subsubsection{Improving skills and labour market participation in rural areas}

Here, the synergies between natural capital and human capital are developed. The need to improve skills in rural areas through higher quality and more accessible education and training programmes is widely recognised. It is mainly suggested to improve rural delivery of education and training, including entrepreneurship and business skills, to reduce the dependence on low-skilled jobs and/or urban centres, based on the recognition that the access to and suitability of training courses are bigger problems than the quantity of training that is available. The provision of forecasting tools and the support to other learning processes such as local actors networking are further strategic orientations.

\subsubsection{Developing infrastructure and services}

The focus here is on developing the synergies between natural capital and physical capital. In both the EU-15 and the NMS, the need to develop infrastructure in rural areas is noted. Transport links need to be improved in order to facilitate the access to education/training, basic services, jobs and markets. There is also a need to develop rural services across the EU, particularly services which are traditionally provided by the public sector such as healthcare, education and social assistance. In the line with the contribution of the above to the quality of life in rural areas, the provision of substantially more affordable homes is suggested so that residents of all ages have the option of living and working in their community.

\subsubsection{Encouraging the development of key growth sectors}

Regarding production based on renewable resources, it is felt that there is still potential for rural job creation in the agri-food chain, especially in the NMS pilot areas. The RuralJobs strategic orientations include the consolidation of farms, increase in competitiveness, diversification, development of food processing, high value added, and development of markets and market institutions.

In the EU-15 pilot areas, much less emphasis is placed on job creation in the agri-food chain, except as part of the green economy. Also as part of the green economy, these latter are the only pilot areas which identify, by implication, the forestry and renewable energy supply chains as activities for creation of new rural jobs. Production based on nonrenewable resources is not included in the strategic orientations of any pilot area.

In terms of consumption by non-residents of the territory including visitors, all pilot areas identify scope for rural job creation in the tourism and leisure sectors. The link between rural tourism and cultural and natural capital is clearly stated here, with an emphasis on the creation of synergies for the development of the tourism and leisure sector as far as the offer and the access to markets are concerned. Such synergy and a full institutional and business awareness of the sustainable use and better valorisation of local resources are also major strategic orientations. Some of the strategic orientations listed above for the agri-food chain also allude to the consumption dimension via topics such as local characteristics, healthy foodstuffs and local products.

The consumption by residents component is only advocated in the EU-15 pilot area reports, in particular the promotion of the establishment in rural areas of businesses (including home based businesses/ consultancies with the possibility to work from home) with low environmental impacts, particularly in the knowledge based services. It is suggested to take advantage of the opportunities offered by the silver economy, which covers the demand for products and services, as well as the mobilisation of savings and of human capital of retired people.

\subsubsection{Reinforcing local rural economy}

This strategic orientation, to some extent, develops the synergy between natural capital and financial capital so as to support the establishment, growth and sustainability of rural businesses, as well as their competitiveness, thereby promoting job creation, either in employment or selfemployment.

Firstly, there are several ways in which business practices can be improved, for instance by setting up a rural-urban private sector-led entrepreneurial learning network in which key private sector businesses should, either by themselves or in partnership with universities and public agencies, establish learning networks to stimulate entrepreneurship through a range of business-focused activities. Marketing innovation is also capital to the growth of businesses and markets.

Another suggestion is to recognise the elderly profile of rural business owners in some sectors, which may be linked to lack of innovation and increased risk of closure of the company, by emphasising takeovers of existing businesses.

Secondly, to support the above, rural business support services should be improved, including at municipal level, 
particularly for small businesses. Rural businesses outside agriculture have almost the same needs as urban ones, but isolation is an issue and rural businesses have less of an understanding and ability to access available support. Support for innovation includes efforts towards the expansion of markets for local endogenous products and goods and the support for the creation of products with declared origin.

Thirdly, there is a need to improve the trading environment for rural businesses in several different ways. Linking two urban areas so as to create an enlarged market (including activity areas, clustering) through collective and coherent governance is suggested in order to reduce territorial competition by giving them slight specialisations according to their assets. Also, the suggestion to increase flexibility of spatial planning is intended to promote more economic activities with low environmental impacts in rural areas, for example via more small serviced office units and live/work units, more tourist activities/accommodation. Coupled with this, it is suggested to promote rural localities as places to accommodate new businesses, emphasising that such areas can offer access to urban-related benefits without the associated diseconomies such as congestion and higher local taxes, and to conduct an audit of rural premises in the sub-region in order to identify structures and areas that could accommodate future business growth, particularly amongst business service activities.

A similar suggestion is to promote reserved land for the development of agricultural structures and local production (short supply chains, organic production), for the development of the green economy (biofuels, green chemistry) and for the development of the silver economy.

Regulation and bureaucracy need to be reduced, especially in the NMS, for instance it is suggested to dissuade permissive regimes, as well as to develop one stop services and e-services via the Internet. Similarly, labour costs need to be reduced so as to boost the labour market.

\subsubsection{Ensuring the proper implementation of the strategy through support actions}

Here the link between natural capital and social capitalrelated issues is explored. There is a need to mobilise the population around the participative approach, which is particularly evident in the NMS. Improving governance in rural areas through bottom-up approach in the definition of strategies and the implementation of local development projects is strongly suggested. In this regard, strengthening Leader and integrating all local public and private stakeholders around local strategic objectives is seen as a way towards such improved governance.

There is also a need to valorise rural areas as places to live, work and play, which is at present mainly recognised in the EU-15 pilot areas only, although an even bigger perception problem seems to exist in the NMS.

RuralJobs recommendations are meant to support the formulation of political priorities for growth and the creation of new jobs in rural areas. At regional and national levels, the recommendations will contribute to underpin core priorities such as the need to bolster education and training, improve the accessibility and attractiveness of rural areas and enhance good governance. The level of knowledge has to be raised so as to optimise the sustainable use of resources, unleash innovation and diversify the economy so as to ensure the competitiveness of businesses. Rural areas ought to be attractive to people for residence, work and leisure, as well as to businesses; accessibility of all to services, goods and information has to be improved. Efforts towards better legislation need to continue so as to improve the business environment and governance as a whole. Raising the level of knowledge of key public and private stakeholders through mutual learning must be scored within an accrued determination to raise the quality of institutions and governance.

Finally, RuralJobs has sought to give a major "visibility" to the diversity of the state of employment in rural areas across the EU. Such attempt has made necessary the definition of types of rural areas within which are brought to light and analysed the complexity of their social and economic situations. RuralJobs recommendations also mean to capitalise on the outcome of such a task by taking them to EU political agenda for jobs and growth. Rural areas need to be more "visible" in the EU 2020 Strategy. Rural development policy should be set within territorial cohesion strategy and must be given major financial and administrative support. Differentiated development priorities must be defined for each rural area on the basis of well defined types.

\subsection{Conclusions of RuralJobs field studies}

The broad conclusions which arise from the RuralJobs pilot areas field studies are that rural areas are typically made up of small settlements that have truncated economies and are highly dependent upon "export-import oriented" businesses. The majority of rural markets are located in urban centres which, by contrast, are much larger settlements with complex internal economic structures that allow for a broader range of goods and services and greater selfsufficiency. Understanding and expanding urban-rural linkages is crucial for effective rural policy, and this reality is reflected in the fact that the potential for new sources of rural employment is interpreted in a regional context. Secondly, 'natural capital' is a potentially important component of this wealth generating capacity (Pakurár et.al, 2010).

Besides, in developed rural areas, information and communication technologies (ICT) and biotechnology have created new employment opportunities. Other areas may be looking for more self-sufficient ways of living ('radical rural'). Alongside this, there are the politics of a new environmentalism and changing opinions about EU subsidies. Agri-industry and the desire for cheap food now sits alongside demands for traceability in food and the reconnection of urban and rural areas through the supply of 
locally produced quality food. Hence, new patterns of consumption are emerging, driven by a range of different forces and demands for different ruralities. These are helping to produce new representations of life, work and play in rural areas. Elsewhere, however, people are finding themselves living in increasingly peripheral areas, lacking employment opportunities and services.

\section{Acknowledgement}

This research was funded by the EU Seventh Framework Programme grant number 211605.

\section{References}

Alkan Olsson, J., Hilding-Rydevik, T., Bradley, K., Routsalainen, A., and Aalbu, H. (2004). Sustainability indicators and monitoring: Discussion paper to the European Regional Network on Sustainable Development, Cardiff, 23-24 March 2004.

Dfid, (1999). Sustainable Livelihoods Guidance Sheet. Department for International Development, London. 36 pp. Available online at http://www.eldis.org/vfile/upload/1/document/0901/section2.pdf Accessed 25 January 2011

Bond, S. and Coombes, M. (2007). 2001-based Travel-To-work Areas Methodology. 3 pp. Available at online at http://www. statistics.gov.uk/geography/downloads/2001_TTWA_Methodology .pdf Accessed 14 April 2008.

Dijkstra, L. and Poelman, H. (2008). Remote Rural Regions: How proximity to a city influences the performance of rural regions. European Union Regional Focus paper no. 01/2008. 8 pp. Available online at http://ec.europa.eu/regional_policy/sources/docgener/ focus/2008_01_rural.pdf. Accessed September 2009
Fieldsend, A. F. (2008). New Sources of Employment to Promote the Wealth-Generating Capacity of Rural Communities. In: Proceedings of the conference: Rural Futures: Dreams, Dilemmas, Dangers, University of Plymouth, UK, 1-4 April 2008. ISBN 9781-84102-185-0. On CD.Fieldsend, 2008.

Fieldsend A. F. (2010). Indicators for the assessment of the potential for employment creation in rural areas. Studies in Agricultural Economics 111, 49-64.

OECD (1994). Creating rural indicators for shaping territorial policy. OECD Publications, Paris, France

Pakurár, M. and Kovács, S. (2008). An overview of current labour market, demographic and economic trends at EU, and national and regional levels. "RuralJobs" Deliverable 2.1.149. pp. Available online at www.ruraljobs.org Accessed 14 September 2009.

Pakurár, M., Oláh, J., Kovács Katonáné, J., Nábrádi, A., Raupeliene, A., Codja, G., Warren, M., Sabau, C., Léger, C., Paquiet, P., Ivanov, B., Popov, R., Vincze, M., Kerekes, K., Veres, E., Pakucs, B., and Szőcs, E. (2010). Synthesis of recommendations RuralJobs strategies for employment in rural araes Censejería de Agricultura y Pesca. Junta de Andalucía 1-120. pp http://www.agora-project.net/

Radvánszki, Á. and Sütő, A. (2007). „Hol a határ?” (Where is the border?) Falu Város Régió, Váti Kht., Budapest, 2007/3, 45-54 pp.

Raupelienè, A. (2009). Review of existing typologies: synthesis report. Deliverable 4.1. of the EU Framework 7 project 'RuralJobs'. 64 pp. Available online at http://www.ruraljobs.org. Accessed September 2009

Sabau, C. and Paquiet, P. (2009). The Rural Labour Market. Deliverable 2.4. of the EU Framework 7 project 'RuralJobs'. 36 Available online at http://www.ruraljobs.org/. Accessed 2 June 2009

Vincze, M., Kerekes, K., Pakucs, B. and Veress, E. (2009). Set of methodologies for collecting data sets from the reference areas. Deliverable 3.1.of the EU Framework 7 project 'RuralJobs'. 63 pp. http://www.ruraljobs.org/. Accessed 23 September 2009. 
